\title{
Retethering : A Neurosurgical Viewpoint
}

\author{
Ji Yeoun Lee, ${ }^{1,2}$ Kyung Hyun Kim, ${ }^{1}$ Kwanjin Park, ${ }^{3}$ Kyu-Chang Wang ${ }^{1}$ \\ Division of Pediatric Neurosurgery, Seoul National University Children's Hospital, Seoul, Korea \\ Department of Anatomy, ${ }^{2}$ Seoul National University College of Medicine, Seoul, Korea \\ Division of Pediatric Urology, ${ }^{3}$ Seoul National University Children's Hospital, Seoul, Korea
}

During the follow-up period after surgery for spinal dysraphism, a certain portion of patients show neurological deterioration and its secondary phenomena, such as motor, sensory or sphincter changes, foot and spinal deformities, pain, and spasticity. These clinical manifestations are caused by tethering effects on the neural structures at the site of previous operation. The widespread recognition of retethering drew the attention of medical professionals of various specialties because of its incidence, which is not low when surveillance is adequate, and its progressive nature. This article reviews the literature on the incidence and timing of deterioration, predisposing factors for retethering, clinical manifestations, diagnosis, surgical treatment and its complications, clinical outcomes, prognostic factors after retethering surgery and preventive measures of retethering. Current practice and opinions of Seoul National University Children's Hospital team were added in some parts. The literature shows a wide range of data regarding the incidence, rate and degree of surgical complications and long-term outcomes. The method of prevention is still one of the main topics of this entity. Although alternatives such as spinal column shortening were introduced, re-untethering by conventional surgical methods remains the current main management tool. Re-untethering surgery is a much more difficult task than primary untethering surgery. Updated publications include strong skepticism on re-untethering surgery in a certain group of patients, though it is from a minority of research groups. For all of the abovementioned reasons, new information and ideas on the early diagnosis, treatment and prevention of retethering are critically necessary in this era.

Key Words : Lumbosacral lipoma · Myelomeningocele · Retethering · Incidence · Outcome.

\section{INTRODUCTION}

During the follow-up period after surgery for spinal dysraphism, such as myelomeningocele (MMC) or lumbosacral lipomatous malformation (LLM), a certain portion of patients show neurological deterioration and secondary phenomena, such as motor, sensory or sphincter changes, foot and spinal deformities, pain, and spasticity. These clinical manifestations are caused by tethering effects on the neural structures at the site of previous operation. This entity, retethering, is also called 'secondary tethered spinal cord syndrome'.

A histological examination of tissues from retethering cases could identify astrocytosis, the appearance of monocytes, activated microglia, and apoptotic cells with the expression of pro-inflammatory and pro-apoptotic mediators such as IL-1 $\beta$ and TNF- $\alpha$ and their receptors, HIF- $1 \alpha /-2 \alpha$, and PARP. These

\footnotetext{
- Received : February 12, 2020 •Revised : February 25, 2020 •Accepted : February 29, 2020

- Address for reprints : Kyu-Chang Wang

Division of Pediatric Neurosurgery, Seoul National University Children's Hospital, 101 Daehak-ro, Jongno-gu, Seoul 03080, Korea Tel : +82-2-2072-3489, Fax : +82-2-2072-0274, E-mail : kcwang@snu.ac.kr, ORCID : https://orcid.org/0000-0001-7440-6650
}

This is an Open Access article distributed under the terms of the Creative Commons Attribution Non-Commercial License (http://creativecommons.org/licenses/by-nc/4.0) which permits unrestricted non-commercial use, distribution, and reproduction in any medium, provided the original work is properly cited. 
findings were also seen in neurons".

The widespread recognition of retethering drew the attention of medical professionals of various specialties because of its incidence, which is not low when surveillance is adequate, and its progressive nature.

This article reviews the literature on the incidence and timing of deterioration, predisposing factors, clinical manifestations, diagnosis, surgical treatment and its complications, clinical outcomes, prognostic factors and preventive measures of retethering. We, the Seoul National University Children's Hospital team, have not yet systematically analyzed our data. However, our current practice and opinions were added in some parts.

In this article, 'retethering' means symptomatic events. Findings in neuroimaging, such as low-lying conus and thinning or stretching of the spinal cord, are not included if asymptomatic. 'Neurological deficits' include symptoms and signs of neurogenic bladder and neurogenic bowel as well as motor, sensory and reflex changes; however, it does not encompass foot and spinal deformities or pain. For some items in this article, the years of publication are included in parentheses to provide readers with an understanding of chronological changes in the level of medical practice.

\section{INCIDENCE AND TIMING OF SYMPTOMATIC RETETHERING}

\section{Incidence}

There are many articles on the incidence of retethering. In the textbook, the incidence of retethering was described as up to $15 \%{ }^{7}$. However, the incidence of retethering was reported to be as high as $>30 \%$ in a series of $>20$ patients with a follow-up of $>5$ years and up to $57 \%$ with a follow-up of $>18$ years ${ }^{8,34,38)}$. Among those, a meta-analysis performed by Goodrich et al. ${ }^{15)}$ in 2016 provided valuable information. The incidence of retethering depends on the interval between the initial surgery and the last follow-up. It is a time-dependent event. According to this meta-analysis of 608 patients from 13 series, there was a significant positive linear correlation between follow-up duration and the percentage of retethering, with an increase of $3.2 \%$ per year, $0 \%$ at 2.1 years and $57 \%$ at 18 years. The detection rate of urological deterioration is higher if urodynamic study (UDS) is adequately performed. Tarcan et al. ${ }^{42}$ reported a similar rate, $32 \%$ rate of neurourological deterioration in 25 patients with a mean follow-up duration of 9.1 years.

\section{Timing of symptomatic retethering}

According to Ostling et al. ${ }^{32}$, retethering usually manifests 5 years after previous untethering surgery. However, the interval between the initial operation and re-untethering surgery also depends on the duration of follow-up, and the reported intervals range widely, from 2 months to more than an average of 100 months $^{18,27)}$. As stated by Al-Holou et al. ${ }^{3)}$ and Goodrich et al. ${ }^{15)}$, at least the whole growing period, up to 18 years of age, seems to be a vulnerable time for retethering.

Filar lipomas are reported to have a low rate of retethering. However, the rate is not negligible even in this type of LLM. Four series showed rates of $2.7-8.6 \%$ with an interval of approximately $4-5$ years after the initial operation ${ }^{31,32,45,47)}$.

\section{PREDISPOSING FACTORS}

\section{Age}

Age is reported as a predisposing factor. The chance of retethering is decreased when the patient has grown up. According to Bowman et al. ${ }^{6}$, the retethering rate decreased to $7.4 \%$ after age 15 and further to $1.8 \%$ after age 20 .

\section{Primary pathology}

Some researchers argued that retethering is significantly more common in LLMs than in $\mathrm{MMC}^{3)}$. However, the results are not consistent among reports. Our experience strongly supports a higher rate in LLM. More severe pre-existing neurological deficits and thinner intradural contents at the lumbosacral region in MMC seem to be related to the lower rate of retethering. In contrast, in low-lying MMC (low sacral) where the neurological deficits are mild and the spinal canal is narrow, the two factors above are absent, and the rate of symptomatic retethering is higher than in MMC of higher location. Conforming to our experience, lower lesion level MMC was reported to predispose patients to symptomatic retethering ${ }^{14)}$.

\section{Duraplasty}

Regarding duraplasty, Samuels et al. ${ }^{36)}$ reported a significantly lower rate of pseudomeningocele or retethering in cases of duraplasty for complex lesions compared with primary du- 
ral closure. Mehta et al. ${ }^{28)}$, on the other hand, showed no difference in retethering rates compared with primary dural closure. However, Pang et al. ${ }^{33)}$ emphasized the importance of the cord/sac ratio in surgery for LLM, recommending radical removal of fat, pial reconstruction sutures and redundant dural grafts. In a detailed study on a large number of patients with radical fat removal and long-term follow-up, they showed groups with good outcome in univariate analysis : age younger than 2 years, absence of symptoms, absence of previous operations and low cord/sac ratio. Among those, only the cord/sac ratio remained as a prognostic factor of retethering in multivariate analysis.

\section{Material of dural graft}

The type of dural graft material does not have an influence. Although some dural substitute materials were previously recommended, none of them seemed effective for the prevention of symptomatic retethering ${ }^{10)}$.

\section{Scoliosis}

According to Mehta et al. ${ }^{28}$, scoliosis was not a predisposing factor, but it was associated with earlier retethering.

In patients who need operations for both retethering and spinal correction/fusion, concurrent operation has a lower retethering rate than two-stage operation (untethering, then spinal correction/fusion), $0 \%$ vs. $9.5 \%$, respectively ${ }^{29)}$. Adhesion after previous untethering surgery may have traction effects during subsequent spinal correction.

\section{CLINICAL MANIFESTATIONS}

On retethering, the patients manifest with neurological deterioration and secondary phenomena such as motor, sensory or sphincter changes, foot and spinal deformities, pain, and spasticity, without other causes.

\section{Type of manifestation}

The order of frequency in the manifesting symptoms was not constant among the articles, and the percentage of the presence of each symptom varied widely. The percentage of the presence of each symptom depends on the level of recognition and the alertness of the management team and caregivers. However, urological and motor symptoms tend to be more common $(>50 \%)$ than others ${ }^{18,26,28)}$. Pain is more frequent in aged children. Regarding the lumbosacral angle, although some supported its relationship to pain and retethering, its clinical value seems unclear ${ }^{11}$.

\section{Type of primary pathology}

Between the MMC and LLM groups, the symptoms of retethering were not different ${ }^{18)}$.

\section{Foot deformity and scoliosis}

In growing children, even without progression of neurologic deficits, imbalance of muscle power may cause the progression of foot deformity. In these patients, neurological examination is important for differentiation from retethering. If the muscle power is decreased or the direction of deformation is changed, retethering is more likely. However, manual muscle testing has a limitation in its objectivity, and caution is needed in the evaluation of deformed ankles. Follow-up electromyography (EMG) data are helpful for differentiation. Theoretically, retethering may involve upper motor neurons only and EMG cannot detect the event. However, our team has not encountered such cases. Lower motor neurons were involved in all of our retethering cases who showed changes in motor power. EMG played a major role in the diagnosis of such cases in our series. It is our routine to confirm the status of the innervation of muscles by EMG when retethering is suspected on manual muscle tests.

In patients with progressive scoliosis, the differentiation of retethering from other causes is important. In general, the speed of progression is rather abrupt and rapid compared to other orthopedic causes. Rapidly progressing scoliosis is a warning sign of retethering.

\section{DIAGNOSIS}

During the follow-up of postoperative spinal dysraphism patients, the possibilities of retethering should be in mind, especially when the patients are still growing. When neurological deterioration and its secondary phenomena, including motor, sensory or sphincter changes, foot and spinal deformities, pain, and spasticity, are detected, diagnostic work-up is necessary to identify other causes. If the changes cannot be explained by other causes, the diagnosis of retethering is 
made. Basically, the diagnosis of retethering is made by the exclusion of other causes. Hydrocephalus with shunt malfunction, Chiari malformation, and proximal syringomyelia in MMC are the 'other causes' of neurological changes. It should be noted that in most cases, the progression of distal syringomyelia is the result of retethering rather than another cause of neurological changes. Urological evaluation, including UDS, is performed for detailed evaluation of voiding function and for differentiation from other urological causes.

\section{EMG}

Follow-up EMG examination looking for changes from previous data is recommended for more objective evaluation if the progression of weakness is suspected by manual muscle test. For this reason, our team routinely obtains baseline EMG data at 6-12 months after the initial untethering surgery unless the primary pathology had a very low rate of retethering, such as thickened filum.

\section{Cerebrospinal fluid study}

Sharma et al. ${ }^{39)}$ reported the results of a cerebrospinal fluid (CSF) study from patients with retethering and found increased concentrations of alanine and lactate. However, a lumbar tap test is almost always unsafe because of the low-lying conus and narrow CSF space in these patients, especially in postoperative LLM cases. It seems not practical.

\section{UDS}

Hayashi et al. ${ }^{18)}$ emphasized the importance of UDS. They found abnormalities in UDS in $98 \%$ of patients with retethering, although only $9 \%$ of them showed urinary incontinence. The most common finding was detrusor overactivity, which was shown in $89 \%$. However, it should be kept in mind that detrusor overactivity is not uncommon in healthy young children. Repeated or follow-up examinations are recommended if the findings are not conclusive.

Our urological colleagues have applied video-UDS in patients with suspected retethering and found that abnormal closing action of the sphincter was associated with the aggravation of the bladder, such as trabeculation. Later, they confirmed that this abnormal movement was associated with electromyographic detrusor-sphincter dyssynergia (DSD) and investigated whether the DSD was shown in patients with other evidence of retethering. They found that 49 out of
53 patients (92\%) who underwent re-untethering surgery showed DSD findings. Furthermore, when they retrospectively reviewed the video-UDS data, this sign of DSD was seen even before the recognition of symptomatic progression caused by retethering. Thus, in patients that show progressive urological problems despite proper urological management, video-UDS should be checked to obtain a possible clue of retethering. Meyrat et al. ${ }^{30)}$ proposed the urodynamic score, which has four components : bladder volume, 0-5; compliance, 0-4; detrusor activity, 0-5; and vesico-sphincteric synergy, 0-3 (total, 0-17) and found its usefulness in the quantification of neurourological function and in the early diagnosis of retethering. Ogiwara et al. ${ }^{31)}$ also paid attention to the UDS findings of large post-void residual volume, decreased bladder capacity, increase in filling pressure, and poor sensation of filling for the diagnosis of retethering.

\section{Neuroimaging}

Basically, retethering is not an entity diagnosed by neuroimaging. However, it is useful for the exclusion of 'other causes' of neurological deterioration such as hydrocephalus, shunt malfunction, Chiari malformation, and proximal syringomyelia in MMC, dermoid cyst and other degenerative spinal disorders. Neuroimaging does not show diagnostically important positive findings for retethering except new onset or progression of syringomyelia. In other words, new onset or progression of syringomyelia may be the only clue of symptomatic retethering. According to Faggin et al. ${ }^{12)}$, 25\% of retethering cases of LLM are associated with terminal syringomyelia. Lee et al. ${ }^{24)}$ showed a case in which the recurrence of syringomyelia preceded symptomatic retethering by 6 months (Fig. 1). Neuroimaging after primary untethering surgery may show progressive thinning with a straightening of the spinal cord. Although it is a finding of physical stretching of the cord, its clinical meaning is not significant because of the low correlation with symptomatic retethering (low specificity). The 'syringomyelia in tethered spinal cord in a general scope' is another topic of this Pediatric Issue 2020.

Stamates et al. ${ }^{40)}$ recommended prone magnetic resonance imaging (MRI) as a diagnostic tool for retethering. They set the cut-off value of ventral movement of the spinal cord on prone imaging as $10 \%$ of the spinal canal width and reported sensitivity and specificity (for necessity of reoperation) as $92.7 \%$ and $100 \%$, respectively. 


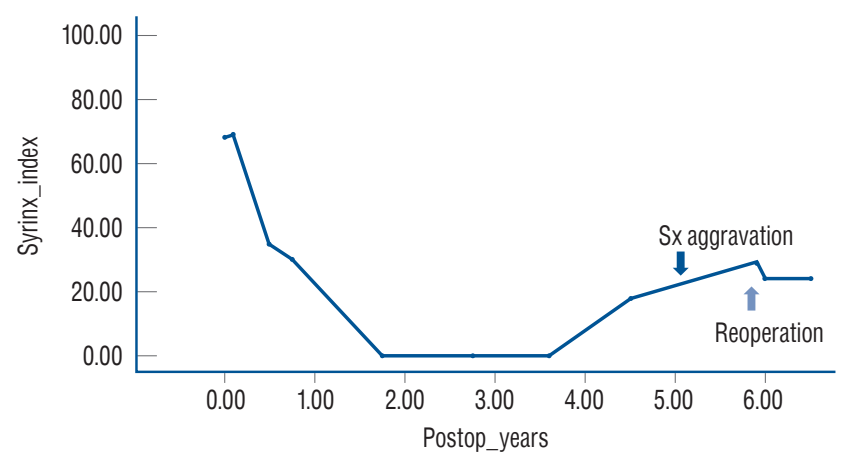

Fig. 1. A graph showing $\mathrm{SI}$ (cross-sectional area of the syrinx as a percentage of the spinal cord area) of a patient with retethering. The syrinx disappeared completely during the 21-month period after the initial untethering surgery. At postoperative 4.5 years, an increase in $\mathrm{SI}$ was noted by sonography, and the patient began to complain of urinary Sx 6 months later (dark arrow). Re-untethering surgery was performed because of the progression of urinary symptoms (light arrow). MRI taken just before the second operation demonstrated further enlargement of the syrinx. Modified from Lee et al. ${ }^{24)}$ with permission from Oxford Academic. Sx : symptoms, SI : syrinx index, MRI : magnetic resonance imaging.

Spinal sonography has been used for the evaluation of spinal cord pulsation. Lam et al. ${ }^{23)}$ set the cut-off value of an amplitude of $0.3 \mathrm{~mm}$ as a warning criterion for retethering, and Schumacher and Richter ${ }^{37)}$ stated the usefulness of spinal sonography with one-dimensional fast Fourier transformation in the measurement of cord mobility and the recognition of retethering. Many years ago, our team tried to determine the value of spinal cord pulsation in the diagnosis of retethering. Our impression was that the preservation of good pulsation seems to indicate that impending symptomatic tethering is unlikely (high negative predictive value), although decreased or absent pulsation does not suggest impending symptomatic retethering (low positive predictive value with low differentiation power). Although clinicians are comfortable when spinal cord pulsation is present, we did not think that spinal sonography for the evaluation of spinal pulsation is cost-effective, and we stopped its use.

\section{SURGICAL TREATMENT}

\section{Indication of re-untethering surgery}

When the diagnosis of retethering is made, a decision on surgery, the only treatment modality, is made, considering the natural course of retethering and possible surgical complica- tions. The usual natural course is progressive; however, it is difficult to predict its end point. Although the end of linear (height) growth does not inflict additional traction physically, the continuous presence of overtraction on neural structures may cause additional neural damage. Therefore, the end of the growth of the child is not a guarantee of safety.

Surgical damage to neural tissue is not negligible during reuntethering operations. A careful balance of the risks and benefits is necessary. The risk depends on the individual patient, type of previous surgery, and experience of the management team. Severe scarring is the most troublesome factor precluding adequate re-untethering. Surgeons tend to be more aggressive when the patients show rapid progression. Our team leans toward aggressive surgical treatment despite a neurological complication rate $>10 \%$ when the patient demonstrates evident urological progression to 'high-pressure bladder'. The protection of renal function is one of the most important goals.

\section{Surgical method}

The surgical method itself is basically not different from the first untethering surgery. However, more fibrous adhesion is encountered. Intraoperative neurophysiological monitoring is an essential tool for the preservation of neurological function and aggressive re-untethering. Maher et al. ${ }^{26)}$ reported the chance of successful complete circumferential re-untethering as $37 \%$. However, the majority of investigators reported a higher percentage as is same in our experience, $>90 \%$.

In some cases, dural opening with 'crotch dissection' is halted by positive responses from intraoperative electrical stimulation. In these cases, we skip the response-positive area and move to a more distal part to make a hole at the responsenegative area. To make a hole in the subarachnoid space correctly, we insert a right-angled dissector into the subarachnoid space from the cranial part and use the tip of the dissector as a guide for distal perforation. Then, crotch dissection is continued to the distal part ${ }^{21}$. After the release of the tethered cord, we frequently find impinged nerve roots at the response-positive point. After release from the impingement, complete reuntethering is possible. However, a small portion of patients show functional nerve roots embedded in the laterally extended fibroadipose tissue. We leave them embedded and intact, although a point of minor tethering remains (Fig. 2).

Repeated surgery makes paravertebral muscles atrophic. 

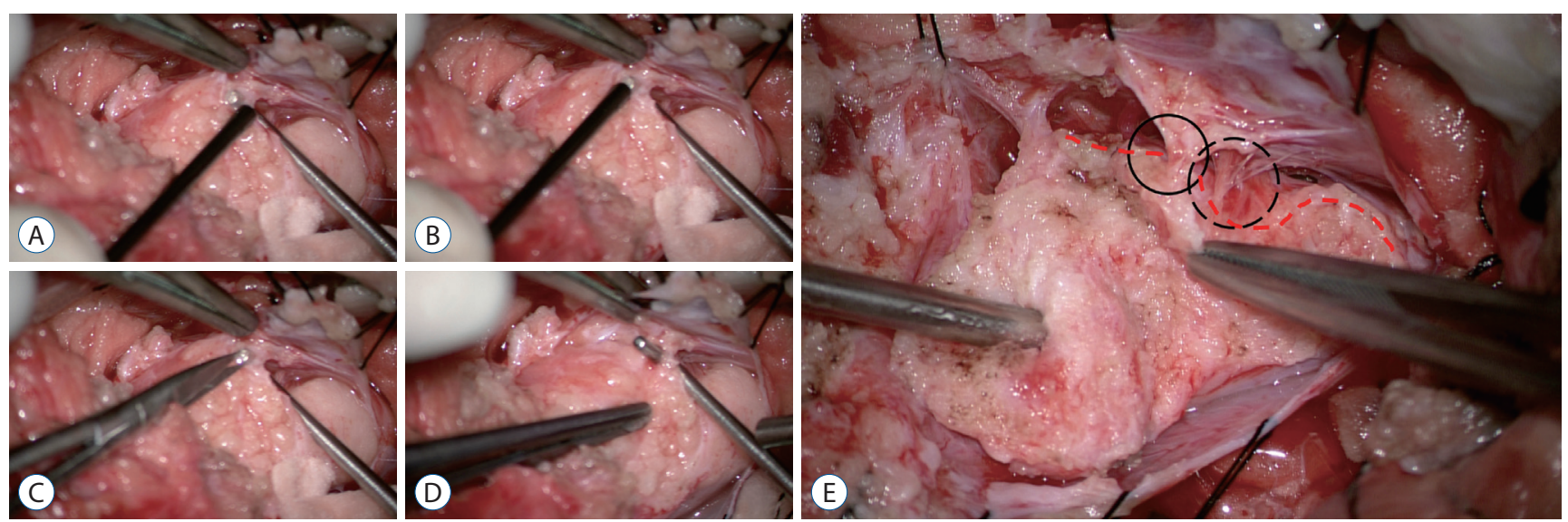

Fig. 2. Operative photographs of skipping the area that shows positive responses on electrical stimulation during the re-untethering surgery. The right side of each photo is the cephalad direction. A and B : Electrical stimulation is performed caudally. At this time, if a positive reaction occurs, stimulation is continued caudally to the site where the response does not occur. A right-angled dissector tip is placed from inside outward at the thinned responsenegative area. C : A new perforation is made on this site using microscissors. D : The hole is identified between the subarachnoid space (SAS) and the new perforation site and is enlarged by the right-angled dissector. From this point, crotch dissection is extended downward. E : The preserved roots at the skipped area (black circle) come from the medial side of the lipoma-cord fusion line (red dashed lines) and are embedded in the fibroadipose tissue closer to the SAS, in contrast to the other roots that are exposed to and run through the SAS (black dotted circle). Dura is tagged separately with black silk. Modified from Kim et al. ${ }^{21)}$ with permission from Elsevier Inc.

The preservation of peri-vertebral soft tissues and the closure of wounds with healthy layers are important for avoiding CSF leakage and pseudomeningocele formation.

\section{Spinal column shortening : an alternative to con- ventional re-untethering surgery}

Spinal column shortening is a recently introduced surgical method for repeated retethering. In 2008, Kanno et al. ${ }^{20)}$ performed spine-shortening osteotomy (SSO) in a patient with T12 vertebral body fracture and LLM (not a case of retethering but a case without any previous untethering surgery) and reported improvement in numbness and tingling sensation in the legs that had been present before trauma. After surgery, the MRI demonstrated the relief of tension on the spinal cord. After that, SSO became a surgical method for the relief of tension on neural structures and began to be applied to patients with repeated retethering ${ }^{22}$. SSO has several advantages. It avoids the risk of neural injury and scar formation caused by direct manipulation of neural structures and CSF-related complications associated with the opening of the dura. On the other hand, the operation has a limitation in the growing spine; it leads to growth retardation or crankshaft deformity ${ }^{2}$.

With a cadaveric tethered cord study, Grande et al. ${ }^{16)}$ demonstrated that a $15-25 \mathrm{~mm}$ thoracolumbar subtraction osteotomy effectively lowered the tension on neural structures. In another cadaveric study by Safain et al. ${ }^{35)}, 12-16 \mathrm{~mm}$ shortening of vertebral column by posterior osteotomy was optimal for adequate tension relief and the minimization of dural buckling.

SSO is commonly performed at the L1 level with fusion between T12 and L2. L1 is a favorable site because injury to T12 or L1 roots does not cause significant neurological deficits. The rarity of dysraphic lesions, relative lack of physiological lordosis or kyphosis, and not much motion (compared with other lumbar levels) at this level are other reasons for the choice of the level for $\mathrm{SSO}^{2,25)}$.

Among a few methods of SSO, pedicle subtraction osteotomy (PSO) is preferred for vertebral column resection. PSO involves removal of bone at the posterior aspect of the vertebral body. It shows less instability, less risk of spinal column translation injury, decreased blood loss, and shorter operation time. However, it is associated with iatrogenic lordosis with sagittal imbalance ${ }^{2)}$.

\section{Spinal cord transection for upper extremity weakness in paraplegic patients}

If a patient is paraplegic and the symptom of retethering is upper extremity weakness, transection at the lower thoracic spinal cord is an option ${ }^{6}$. However, Garces et al. ${ }^{13)}$ reported an adult case of post-transection autonomic dysreflexia as a ma- 
jor complication, even though the level of transection was lower than the thoracic spinal cord.

\section{NEUROLOGICAL COMPLICATIONS}

Neurological deterioration is not a rare complication. The rate is reported as $<4 \%$ in a few articles ${ }^{6,18,43)}$ and $6 \%(1 / 16$ LMM re-untethering patients) in the series of Pierre-Kahn et al. ${ }^{34)}$. However, our experience shows a rate of neurological deterioration of $>10 \%$. According to Sun et al. ${ }^{41}$, the worsening of weakness by surgery was more likely if the symptom of retethering was motor weakness. Transient lower leg paresthesia is much more common and is reported in up to $79 \%$ of patients $^{18)}$.

\section{CLINICAL OUTCOMES}

\section{Complete untethering}

Complete untethering was possible in $93-100 \%$ of cases $^{17-19}$. Our experience also showed a similar result of $>90 \%$. Generally, the degree of technical difficulty of re-untethering is much higher than that of the first untethering surgery. However, the progressive nature of the preoperative clinical manifestations in retethering, especially when they endanger renal function, makes surgeons more aggressive for complete untethering.

\section{General outcome}

There are many articles reporting high rates of favorable outcome (improvement or stabilization) on short-term and long-term post re-untethering follow-up studies, $>70 \%$, up to $>90 \%$. Herman et al..$^{19)}$ reported $93 \%$ stabilization or improvement, $7 \%$ progression in patients with MMC and $100 \%$ stabilization or improvement in patients with LLM at an average follow-up of 4 years. According to Pierre-Kahn et al. ${ }^{34)}$, among the 16 re-untethered LLM patients, five (31\%) improved, seven (44\%) patients' progression stopped, three (19\%) patients' deterioration continued, and one (6\%) patient worsened (favorable $75 \%$ ). Haberl et al. ${ }^{17)}$ showed 26\% significant improvement, 58\% stabilization and 16\% deterioration (including all four incomplete re-untethering cases) (favorable 84\%) with a follow-up of $>4.8$ years in 77 patients. Martínez-Lage et al. ${ }^{27)}$ demonstrated that eight patients improved, two patients stabilized, and one patient worsened (91\% favorable) among $11 \mathrm{MMC}$ patients with progressive retethering symptoms after an average follow-up of 5.5 years. According to Thuy et al. ${ }^{43}$, the improvement or resolution rate was $26.7 \%$, and the rate was higher in patients with motor (36.4\%) and sphincteric dysfunction (27.3\%).

On the other hand, Sun et al. ${ }^{41)}$ were rather pessimistic regarding the outcome of re-untethering surgery. They stressed a low rate of symptomatic improvement (0-18.8\% depending on symptoms) and a high rate of deterioration by re-untethering surgery (20.0-35.3\%). They encouraged conservative treatment for patients with retethering, pointing out the higher possibility of deterioration caused by surgical injury rather than improvement in patients with motor and sphincter dysfunctions.

\section{Motor symptoms}

The reported rate of improvement in motor or gait function ranges widely, $11.8 \%{ }^{41)}, 26 \%{ }^{28)}, 70 \%{ }^{6}$, and $100 \%{ }^{18)}$, whereas the reported deterioration rates are $11 \%^{28)}$ and $17.7 \%{ }^{41)}$. Our experience supports the results of Sun et al. ${ }^{41}$, who described a low rate of improvement and a high rate of surgery-induced deterioration. We do not recommend surgery for patients who show only slow, mild progression of motor power.

According to Bowman et al. ${ }^{6}$, , spasticity was improved in two-thirds of patients, and contracture was stable in $78 \%$ of patients after surgery.

\section{Sensory symptoms}

The reported rate of sensory symptom improvement also ranges widely, $18.8 \%{ }^{41)}, 26 \%{ }^{28)}$, and $94 \%^{18)}$. Sun et al. ${ }^{41)}$ reported surgery-induced deterioration of sensory function in $17.7 \%$.

\section{Bladder function}

Although Sun et al. ${ }^{41)}$ recommended conservative management for bladder dysfunction, reporting postoperative improvement in $0 \%$ and deterioration in $31.3 \%$, generally, the outcome of urological function looks favorable. In terms of urodynamic outcome, the postoperative favorable outcome is more evident : increased bladder volume, decreased detrusor overactivity and improvement of DSD. The postoperative changing pattern of bladder compliance seems to differ de- 
pending on the status of bladder wall fibrosis.

Abrahamsson et al. ${ }^{1)}$ reported excellent urodynamic results after re-untethering surgery in 20 patients with MMC. Postoperatively, 35\% of the patients showed improved bladder function, and 5\% deteriorated. All patients who had preoperative deterioration improved, and 90\% of those who were stable before surgery remained stable after surgery. They emphasized the importance of regular urodynamic evaluation for the early detection of retethering in children with MMC. Maher et al. ${ }^{26)}$ and Bowman et al. ${ }^{6}$ reported rates of improvement in urinary symptoms as 53\% and 64\%, respectively. According to Mehta et al. ${ }^{28)}$, urinary symptoms were improved in $17 \%$, maintained in $76 \%$, and worsened in $7 \%$ with a mean follow-up duration of 47 months in retethered MMC patients. Hayashi et al. ${ }^{18)}$ reported improvement rates of $80 \%$ in urinary incontinence and $75 \%$ in detrusor overactivity. Their postoperative UDSs revealed a significant increase in bladder volume but no changes in bladder compliance. Preoperative detrusor overactivity, which was considered to be the most significant indicator for the early diagnosis of retethering, was improved by 75\% after surgery. According to Alzahrani et al. ${ }^{4)}$, UDS parameters that revealed postoperative improvement most were intravesical pressure at total cystometric bladder capacity and bladder compliance.

It is common to find trabeculation of the bladder, which is regarded as the result of long-standing detrusor overactivity,
DSD and associated high-pressure bladder. It has been widely believed that the morphological changes of the bladder are caused by fibrosis and are an irreversible phenomenon. Thus, augmentation cystoplasty is offered as the last resort. However, our experience showed that augmentation cystoplasty could be avoided with properly performed re-untethering surgery. Our cohort included 13 patients in whom augmentation cystoplasty was offered at other hospitals or was considered by our team. Following successful re-untethering surgery, all patients experienced urodynamic improvement of the bladder, at least obviating the need for augmentation cystoplasty. Furthermore, all of them showed the reversal of bladder trabeculation. During the follow-up of 3-5 years after surgery, five patients experienced remarkable changes in bladder shape, as shown in Fig. 3. Given that augmentation cystoplasty has myriads of metabolic and long-term complications inherent to the breakage of the normal integrity of the bladder at the cost of the preservation of renal function, the value of surgery avoidance and the normalization of bladder function can be enormous. In selected patients, the disadvantages of augmentation cystoplasty may exceed the risk of re-untethering surgery.

\section{Bowel function}

As in bladder function, Sun et al. ${ }^{41)}$ reported poor outcome of bowel function : bowel function improved in 5.9\%, whereas

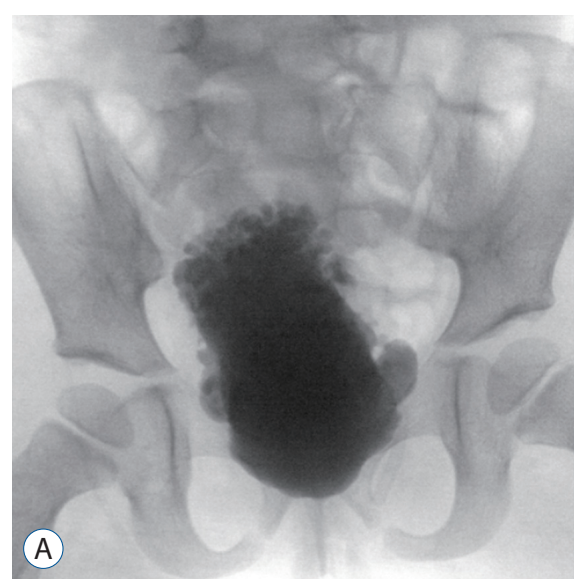

2015, before re-untethering

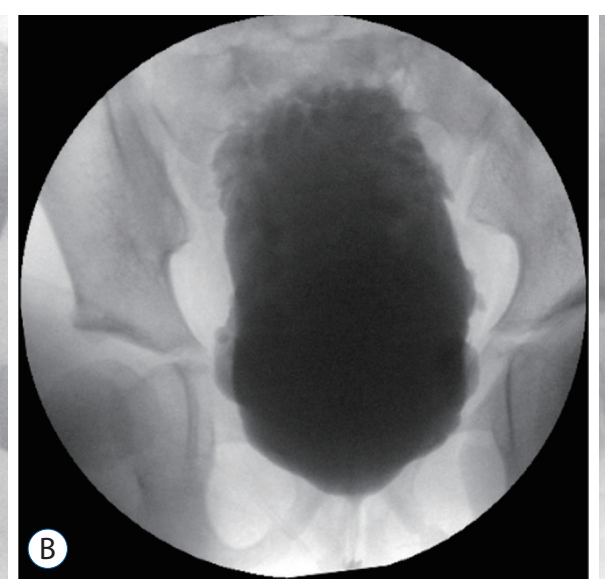

2018, P0 2 years

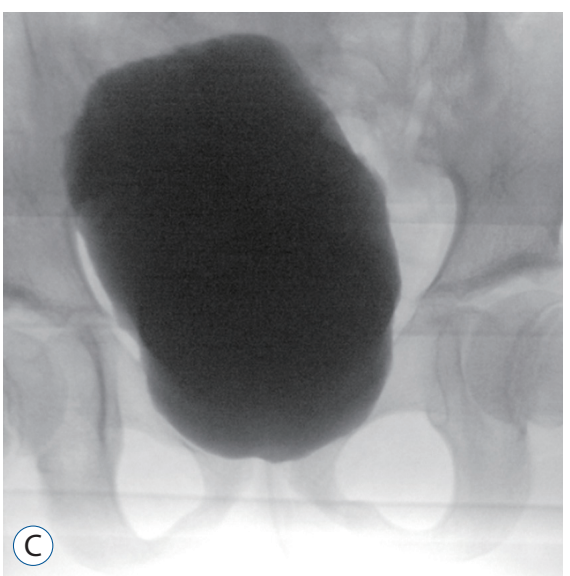

2020, PO 4 years

Fig. 3. Serial changes of bladder shapes following re-untethering surgery. The girl had undergone primary untethering surgery for myelomeningocele just after birth. Despite management with clean intermittent catheterization and anticholinergic medication, her bladder capacity was not changed with increasing age (2015, 3 years old). Morphologically, her bladder was deformed significantly with increased trabeculation (A : See the upper side of the bladder). Following re-untethering surgery on January 2016, the trabeculation became flattened with the normalization of vesical pressure (B). At 4 years after re-untethering surgery, the significant bladder trabeculation seen in the upper wall was nearly normalized (C). PO : postoperative. 
it deteriorated in $35.3 \%$ by re-untethering surgery.

\section{Pain}

The response of pain to re-untethering surgery is reportedly excellent, although a few studies have shown low improvement rates. The reported response rates were $13.1 \%{ }^{41)}, 28 \%{ }^{28)}$, $81 \%{ }^{26)}$, and $100 \%{ }^{6}$, and the deterioration rates were $7 \%{ }^{28)}$ and $10.0 \%{ }^{41)}$. Our experience revealed that patients who complained of pain were older and that the response to surgery was excellent. The majority of patients described a change in pain character just after surgery, and the 'changed pain' gradually improved during a period of up to a few years, mostly within several months.

\section{Deformity and scoliosis}

As expected, ankle deformity and scoliosis showed no improvement after re-untethering surgery ${ }^{18)}$. Despite re-untethering surgery, up to $52 \%$ of patients with scoliosis showed progression, and $28 \%$ required spinal fusion ${ }^{6}$, especially when the degree of preoperative scoliosis was severe.

\section{Outcome of cord transection}

The response of upper extremity motor power to the transection of the lower spinal cord in patients with paraplegia was generally good ${ }^{6}$.

\section{Outcome of spinal column shortening}

Aldave et al. ${ }^{2)}$ reported a favorable outcome of spinal column shortening, showing postoperative symptomatic improvement in five out of seven retethering patients.

\section{PROGNOSTIC FACTORS}

Herman et al. ${ }^{19)}$ reported that the outcome of retethered MMC patients was slightly less favorable than that of retethered LLM patients during the mean follow-up of 4 years : $93 \%$ vs. $100 \%$ improvement or stabilization of presenting complaints.

Maher et al. ${ }^{26)}$ stated that as the number of prior untethering operations was increased, the rate of pain relief was decreased, and the chance of significant morbidity was increased. In addition, they described the positive value of incomplete but extensive re-untethering for clinical improve- ments.

According to Al-Holou et al. ${ }^{3)}$, younger age at re-untethering was a significant prognostic factor of worse long-term neurological outcome, whereas sex, original diagnosis (MMC vs. LLM), spinal level of the lesion, the number of previous untethering operations, and the degree of re-untethering had no impact. Although LLMs and multiple repeated untethering operations are associated with higher rates of incomplete untethering, they were not significant prognostic factors.

Our experience showed worse outcomes of LLM compared to MMC. LLM is accompanied by higher surgical injury because of the significantly higher complexity of the retethered lesion. Thicker intradural contents and pre-existing milder neurological deficits in LLM seemed to be other reasons for the difference.

\section{PREVENTION}

Although several ideas were suggested for the prevention of retethering, none of them was widely accepted except for the reduction of the cord/dural sac ratio proposed by Pang et al. ${ }^{33)}$ as described in the 'Predisposing factors' section of this article.

In 2005, Blount et al. ${ }^{5)}$ reported $0 \%$ retethering in 14 paraplegic MMC patients during the period of $>11$ years after sectioning the normal spinal cord just above the lesion. Sectioning of the normal spinal cord just above the lesion prevents the occurrence of high-pressure bladder, avoids renal injury and negates the need for augmentation cystoplasty. Despite the merit of renal protection, however, the majority of surgeons are hesitant to perform this rather radical operation on newborns with MMC.

In 2006, Tubbs and Oakes ${ }^{44)}$ proposed retention sutures that traverse the intradural space behind the spinal cord. The sutures may keep the dorsal surface of the spinal cord away from the dura and prevent adhesion between them. They reported $0 \%$ retethering in 20 (10 for initial untethering, 10 for re-untethering) patients with a mean follow-up of 8 years.

In 2018, Walker et al. ${ }^{46)}$ reported the value of the human amniotic membrane, which is immune-privileged and has antifibrogenic properties, for the prevention of retethering. However, the short follow-up of 14 months precludes any conclusion at this time. 


\section{CONCLUSION}

Retethering is obviously a major clinical burden for pediatric or spine neurosurgeons and their teams as well as the patients and their families. Repeated retethering with progressive clinical features in some patients, significant surgeryinduced neurological aggravation shown in a not small portion of patients, and gradual decay of surgical benefits over long-term follow-up often lead clinicians to face a distressing dilemma.

The literature shows a wide range of data regarding the incidence, rate and degree of surgical complications and longterm outcomes. The method of prevention is still one of the main topics of this entity. Although alternatives such as spinal column shortening were introduced, re-untethering by conventional surgical methods remains the current main management tool. Moreover, re-untethering surgery is a much more difficult task than primary untethering surgery. Re-untethering surgery requires a long and high learning curve for surgeons, which is sometimes accompanied by a painful experience of surgeons. Updated publications include strong skepticism on re-untethering surgery in a certain group of patients, though it is from a minority of research groups.

For all of the abovementioned reasons, new information and ideas on the early diagnosis, treatment and prevention of retethering are critically necessary in this era.

\section{CONFLICTS OF INTEREST}

No potential conflict of interest relevant to this article was reported.

\section{INFORMED CONSENT}

This type of study does not require informed consent.

\section{AUTHOR CONTRIBUTIONS}

\author{
Conceptualization : KCW \\ Data curation : KP, KCW \\ Formal analysis : KHK, KP, KCW
}

Funding acquisition : JYL, KCW

Methodology: JYL, KCW

Project administration : KCW

Visualization : KHK, KP, KCW

Writing - original draft : JYL, KP, KCW

Writing - review \& editing : KHK, KCW

\section{ORCID}

Ji Yeoun Lee https://orcid.org/0000-0003-0464-7605

Kyung Hyun Kim https://orcid.org/0000-0002-8238-2043

Kwanjin Park https://orcid.org/0000-0002-8926-3047

Kyu-Chang Wang https://orcid.org/0000-0001-7440-6650

\section{- Acknowledgements}

This work was supported by the National Research Foundation of Korea (NRF) Grant funded by the Korean Government (MSIP) (No. NRF-2018R1A5A2025964).

\section{References}

1. Abrahamsson K, Olsson I, Sillén U : Urodynamic findings in children with myelomeningocele after untethering of the spinal cord. J Urol 177 : 331-334; discussion 334, 2007

2. Aldave G, Hansen D, Hwang SW, Moreno A, Briceño V, Jea A : Spinal column shortening for tethered cord syndrome associated with myelomeningocele, lumbosacral lipoma, and lipomyelomeningocele in children and young adults. J Neurosurg Pediatr 19 : 703-710, 2017

3. Al-Holou WN, Muraszko KM, Garton HJ, Buchman SR, Maher CO : The outcome of tethered cord release in secondary and multiple repeat tethered cord syndrome. J Neurosurg Pediatr 4 : 28-36, 2009

4. Alzahrani A, Alsowayan O, Farmer JP, Capolicchio JP, Jednak R, ElSherbiny $\mathrm{M}$ : Comprehensive analysis of the clinical and urodynamic outcomes of secondary tethered spinal cord before and after spinal cord untethering. J Pediatr Urol 12 : 101.e1-e6, 2016

5. Blount JP, Tubbs RS, Okor M, Tyler-Kabara EC, Wellons JC 3rd, Grabb PA, et al. : Supraplacode spinal cord transection in paraplegic patients with myelodysplasia and repetitive symptomatic tethered spinal cord. J Neurosurg 103(1 Suppl) : 36-39, 2005

6. Bowman RM, Mohan A, Ito J, Seibly JM, McLone DG : Tethered cord release: a long-term study in 114 patients. J Neurosurg Pediatr 3 : 181187, 2009

7. Bragg TM, Iskandar BJ : Lipomyelomeningocele in Winn HR (ed) : Youmans and Winn Neurological Surgery, ed 7. Philadelphia : Elsevier, 
2017, Vol 2, pp1834-1841

8. Cochrane DD : Cord untethering for lipomyelomeningocele : expectation after surgery. Neurosurg Focus 23 : E9, 2007

9. Cohrs G, Drucks B, Sürie JP, Vokuhl C, Synowitz M, Held-Feindt J, et al. : Expression profiles of pro-inflammatory and pro-apoptotic mediators in secondary tethered cord syndrome after myelomeningocele repair surgery. Childs Nerv Syst 35 : 315-328, 2019

10. Colak A, Pollack IF, Albright AL : Recurrent tethering: a common longterm problem after lipomyelomeningocele repair. Pediatr Neurosurg 29 : 184-190, 1998

11. Cornips EM, Razenberg FG, van Rhijn LW, Soudant DL, van Raak EP, Weber JW, et al. : The lumbosacral angle does not reflect progressive tethered cord syndrome in children with spinal dysraphism. Childs Nerv Syst 26 : 1757-1764, 2010

12. Faggin $R$, Drigo $P$, Denaro L, Sartori $S$, d'Avella D : Hydromyelia associated with spinal lipoma of the conus: case report. Spine (Phila Pa 1976) 35 : E1069-E1071, 2010

13. Garces J, Mathkour M, Scullen T, Kahn L, Biro E, Pham A, et al. : First case of autonomic dysreflexia following elective lower thoracic spinal cord transection in a spina bifida adult. World Neurosurg 108 : 988. e1-988.e5, 2017

14. George TM, Fagan LH : Adult tethered cord syndrome in patients with postrepair myelomeningocele: an evidence-based outcome study. J Neurosurg 102(2 Suppl) : 150-156, 2005

15. Goodrich DJ, Patel D, Loukas M, Tubbs RS, Oakes WJ : Symptomatic retethering of the spinal cord in postoperative lipomyelomeningocele patients : a meta-analysis. Childs Nerv Syst 32 : 121-126, 2016

16. Grande AW, Maher PC, Morgan CJ, Choutka O, Ling BC, Raderstorf TC, et al. : Vertebral column subtraction osteotomy for recurrent tethered cord syndrome in adults : a cadaveric study. J Neurosurg Spine 4 : 478-484, 2006

17. Haberl H, Tallen G, Michael T, Hoffmann K, Benndorf G, Brock M : Surgical aspects and outcome of delayed tethered cord release. Zentralbl Neurochir 65 : 161-167, 2004

18. Hayashi T, Takemoto J, Ochiai T, Kimiwada T, Shirane R, Sakai K, et al. : Surgical indication and outcome in patients with postoperative retethered cord syndrome. J Neurosurg Pediatr 11 : 133-139, 2013

19. Herman JM, McLone DG, Storrs BB, Dauser RC : Analysis of 153 patients with myelomeningocele or spinal lipoma reoperated upon for a tethered cord. Pediatr Neurosurg 19 : 243-249, 1993

20. Kanno H, Aizawa T, Ozawa H, Hoshikawa T, Itoi E, Kokubun S : Spineshortening vertebral osteotomy in a patient with tethered cord syndrome and a vertebral fracture. Case report. J Neurosurg Spine 9 : 62-66, 2008

21. Kim KH, Chong S, Lee JY, Kim SK, Cho BK, Wang KC : A Method of untethering by skipping the area of positive responses on electrical stimulation during surgery of lumbosacral lipomatous malformation : "hopping on a stepping stone". World Neurosurg $124:$ 48-51, 2019

22. Kokubun S, Ozawa H, Aizawa T, Ly NM, Tanaka Y : Spine-shortening osteotomy for patients with tethered cord syndrome caused by lipomyelomeningocele. J Neurosurg Spine 15 : 21-27, 2011
23. Lam WW, Ai V, Wong V, Lui WM, Chan FL, Leong L : Ultrasound measurement of lumbosacral spine in children. Pediatr Neurol 30 : 115121, 2004

24. Lee JY, Phi JH, Cheon JE, Kim SK, Kim IO, Cho BK, et al. : Preuntethering and postuntethering courses of syringomyelia associated with tethered spinal cord. Neurosurgery $71: 23-29,2012$

25. Lin W, Xu H, Duan G, Xie J, Chen Y, Jiao B, et al. : Spine-shortening osteotomy for patients with tethered cord syndrome : a systematic review and meta-analysis. Neurol Res $40:$ 340-363, 2018

26. Maher CO, Goumnerova L, Madsen JR, Proctor M, Scott RM : Outcome following multiple repeated spinal cord untethering operations. J Neurosurg 106(6 Suppl) : 434-438, 2007

27. Martínez-Lage JF, Ruiz-Espejo Vilar A, Almagro MJ, Sánchez del Rincón I, Ros de San Pedro J, Felipe-Murcia M, et al. : Spinal cord tethering in myelomeningocele and lipomeningocele patients: the second operation. Neurocirugia (Astur) $18: 312-319,2007$

28. Mehta VA, Bettegowda C, Ahmadi SA, Berenberg P, Thomale UW, Haberl EJ, et al. : Spinal cord tethering following myelomeningocele repair. J Neurosurg Pediatr 6 : 498-505, 2010

29. Mehta VA, Gottfried ON, McGirt MJ, Gokaslan ZL, Ahn ES, Jallo GI : Safety and efficacy of concurrent pediatric spinal cord untethering and deformity correction. J Spinal Disord Tech 24 : 401-405, 2011

30. Meyrat BJ, Tercier S, Lutz N, Rilliet B, Forcada-Guex M, Vernet 0 : Introduction of a urodynamic score to detect pre- and postoperative neurological deficits in children with a primary tethered cord. Childs Nerv Syst $19: 716-721,2003$

31. Ogiwara H, Lyszczarz A, Alden TD, Bowman RM, McLone DG, Tomita T : Retethering of transected fatty filum terminales. J Neurosurg Pediatr $7: 42-46,2011$

32. Ostling LR, Bierbrauer KS, Kuntz C 4th : Outcome, reoperation, and complications in 99 consecutive children operated for tight or fatty filum. World Neurosurg 77 : 187-191, 2012

33. Pang D, Zovickian J, Oviedo A : Long-term outcome of total and neartotal resection of spinal cord lipomas and radical reconstruction of the neural placode, part II : outcome analysis and preoperative profiling. Neurosurgery 66 : 253-272; discussion 272-273, 2010

34. Pierre-Kahn A, Zerah M, Renier D, Cinalli G, Sainte-Rose C, LellouchTubiana A, et al. : Congenital lumbosacral lipomas. Childs Nerv Syst 13 : 298-334; discussion 335, 1997

35. Safain MG, Burke SM, Riesenburger RI, Zerris V, Hwang SW : The effect of spinal osteotomies on spinal cord tension and dural buckling: a cadaveric study. J Neurosurg Spine 23 : 120-127, 2015

36. Samuels R, McGirt MJ, Attenello FJ, Garcés Ambrossi GL, Singh N, Solakoglu $C$, et al. : Incidence of symptomatic retethering after surgical management of pediatric tethered cord syndrome with or without duraplasty. Childs Nerv Syst 25 : 1085-1089, 2009

37. Schumacher $R$, Richter $D$ : One-dimensional fourier transformation of $M$-mode sonograms for frequency analysis of moving structures with application to spinal cord motion. Pediatr Radiol 34 : 793-797, 2004

38. Segal LS, Czoch W, Hennrikus WL, Wade Shrader M, Kanev PM : The spectrum of musculoskeletal problems in lipomyelomeningocele. J Child 
Orthop $7:$ 513-519, 2013

39. Sharma U, Pal K, Pratap A, Gupta DK, Jagannathan NR : Potential of proton magnetic resonance spectroscopy in the evaluation of patients with tethered cord syndrome following surgery. J Neurosurg 105(5 Suppl) : 396-402, 2006

40. Stamates MM, Frim DM, Yang CW, Katzman GL, Ali S : Magnetic resonance imaging in the prone position and the diagnosis of tethered spinal cord. J Neurosurg Pediatr 21 : 4-10, 2018

41. Sun J, Zhang Y, Wang H, Wang Y, Yang Y, Kong Q, et al. : Clinical outcomes of primary and revision untethering surgery in patients with tethered cord syndrome and spinal bifida. World Neurosurg 116 : e66e70, 2018

42. Tarcan T, Bauer S, Olmedo E, Khoshbin S, Kelly M, Darbey M : Long-term followup of newborns with myelodysplasia and normal urodynamic findings : is followup necessary? J Urol 165 : 564-567, 2001
43. Thuy M, Chaseling R, Fowler A : Spinal cord detethering procedures in children: a 5 year retrospective cohort study of the early post-operative course. J Clin Neurosci 22 : 838-842, 2015

44. Tubbs RS, Oakes WJ : A simple method to deter retethering in patients with spinal dysraphism. Childs Nerv Syst 22 : 715-716, 2006

45. Vassilyadi $M$, Tataryn $Z$, Merziotis $M$ : Retethering in children after sectioning of the filum terminale. Pediatr Neurosurg 48 : 335-341, 2012

46. Walker CT, Godzik J, Kakarla UK, Turner JD, Whiting AC, Nakaji P : Human amniotic membrane for the prevention of intradural spinal cord adhesions: retrospective review of its novel use in a case series of 14 patients. Neurosurgery 83 : 989-996, 2018

47. Yong RL, Habrock-Bach T, Vaughan M, Kestle JR, Steinbok P : Symptomatic retethering of the spinal cord after section of a tight filum terminale. Neurosurgery 68 : 1594-1601; discussion 1601-1602, 2011 